\title{
Engaging with Children and Adolescents: A Systematic Review of Participatory Methods and Approaches in Research Informing the Development of Health Resources and Interventions
}

\author{
Kate Freire $^{1}$ DD $\cdot$ Rod Pope $^{2} \cdot$ Kate Jeffrey $^{3} \cdot$ Kristen Andrews $^{2} \cdot$ Melissa Nott $^{1} \cdot$ Tricia Bowman $^{4}$
}

Received: 15 October 2021 / Accepted: 10 January 2022 / Published online: 3 February 2022

(c) The Author(s) 2022

\begin{abstract}
In research, participatory approaches involve engaging in the research with people and empower co-researchers to have a voice. The aim of this review was to synthesize the methods and approaches used to enable children, adolescents, and families to be involved in a participatory approach in research conducted to inform development of health resources and interventions aimed at children and adolescents. Key databases were searched systematically using key word and subject heading searches and included studies were appraised for both methodological quality and sufficiency of reporting of their participatory approach. Findings were synthesized using a critical narrative approach. Among 26 eligible studies, commonly reported participatory approaches involved community-based participatory research, codesign, participatory design, coproduction, and user-centred design. A need was identified to involve co-researchers more in the later stages of participatory approaches. Most studies were of low to moderate methodological quality. A wide variety of methods and activities were used in the studies to enable children to participate in the research, but few studies provided sufficient evidence of their participatory approach. This review concludes that reporting of participatory approaches might benefit from the guidelines that acknowledge the dual nature of participatory approaches as both a research method and an approach that enables action and change.
\end{abstract}

Keywords Participatory approach $\cdot$ Co-production $\cdot$ Co-design $\cdot$ Co-research $\cdot$ Child $\cdot$ Adolescent

Kate Freire

kfreire@csu.edu.au

Rod Pope

rpope@csu.edu.au

Kate Jeffrey

katej@ royalfarwest.org.au

Kristen Andrews

krandrews@csu.edu.au

Melissa Nott

mnott@csu.edu.au

Tricia Bowman

tbowman@csu.edu.au

1 Three Rivers Department of Rural Health, Charles Sturt University, Elizabeth Mitchell Drive, Albury, NSW 2640, Australia

2 School of Allied Health, Exercise and Sports Sciences, Charles Sturt University, Albury, Australia

3 Royal Far West, Manly, NSW, Australia

4 Division of Library Services, Charles Sturt University, Albury, Australia

\section{Introduction}

Worldwide, there is an increasing expectation that end-users are included in research teams conducting studies to inform the co-creation of health resources and interventions. Participatory approaches are thought to increase health equity and literacy (Boyce \& Brown, 2017). Recently, there has been an increase in published literature using these approaches in research across a wide range of populations including children and adolescents (Bradbury-Jones et al., 2018). Yet, there is a limited evidence base for participatory approaches in research (Durose et al., 2017). In contrast to the many guides, mostly for adult populations, that inform researchers and clinicians on how to engage in the participatory production of health interventions and resources, there are few critical reviews that provide evidence-based guidance on the most ethical and successful ways to children and adolescents engage in a participatory research approach. This study systematically reviews the current evidence on the use of participatory methods and approaches in the development 
of health resources and interventions targeted at children and adolescents.

Although there is not one agreed definition for participatory approaches in research, one key attribute all approaches have in common is that they seek to engage in research with people rather than do research to people (Baum et al., 2006). By involving the end user in research activities, these approaches facilitate action, which makes them ideal to use in the development of interventions and resources (Baum et al., 2006). Participatory approaches stem from critical theory and constructivism paradigms but contemporary participatory approaches may use a wide range of qualitative or quantitative methodologies and methods (Richardson, 2014). Their origins have been attributed to Paulo Freire's work with disadvantaged communities in Brazil, whereby a participatory approach was used to empower communities to evaluate the causes of their poverty (Freire, 1972). It is this ethos, to energise communities to have a voice and promote action, that underpins participatory approaches as more than a methodology as it includes elements of an intervention too. This dual feature of both methodology and intervention adds to the complexity of evaluating a participatory approach.

Since Article 12 of the United Nations Convention on the Rights of the Child (1989) was established, there has been an increased awareness of the rights of children and subsequently an increased effort to enable a child's voice to be heard on matters that concern them (Hill, 2006). This has resulted in increasing levels of child and adolescent involvement in participatory approaches to research. Interestingly, it appears there has been greater focus in published literature on participation of children and adolescents who are older, healthy, and neurotypical rather than those deemed more 'vulnerable' due to their age, health condition, or social circumstances (Bradbury-Jones et al., 2018). Children and adolescents who have complex developmental needs are part of this vulnerable group. They may have an identified developmental condition, such as Attention Deficit Hyperactivity Disorder (ADHD), or Developmental Coordination Disorder, or a speech-language disorder; or they might be falling short of developmental milestones without an identified developmental disorder. Management and treatment of these conditions require children, adolescents, and their families to engage with regular programs and therapy thus utilizing interventions and resources frequently.

Participatory approaches have been identified as ideal approaches to use with children and adolescents due to their careful attention to power relationships (Baum et al., 2006). However, the use of a participatory approach should not lead the reader to assume that a child or adolescent was actively included in the research or in decision making around the research, as there are numerous examples of perfunctory 'participation' in the current literature. Several different frameworks have been developed, to describe the level of engagement by the child in research and inform researchers' decision making. Examples of engagement frameworks include: Hart's Participation Ladder (Hart, 1997), a framework for understanding children's' roles in technology design (Druin, 2002), and Sheir's levels of participation (Shier, 2001). Hart's Participation Ladder is the most granular, providing clear descriptors of eight levels, from "manipulation" at level 1 to "child-initiated shared decisions with adults" at level 8. Druin's and Shier's frameworks had four and five levels respectively. Hart's Participation Ladder was used in this review to ensure that all included studies involved an authentic level of participation. The bottom three levels: "manipulation", "decoration" and "tokenism"- were defined by Hart as non-participation, with level 4 ("assigned but informed") and upwards demonstrating increasing levels of participation. This review focuses on research that involved child and family participation consistent with level 4 or above on Hart's Participation Ladder.

\section{Current Study}

There is a limited evidence base for the use, in research, of participatory approaches with children and adolescents. The aim of this review was to identify and synthesize information regarding the methods and approaches used to enable children, adolescents, families, and carers to be involved in a participatory approach in research intended to inform development, and in some cases evaluation, of health resources or interventions designed for children and adolescents. The following research questions were developed to guide this aim. When in the research process and resource or intervention development were participatory approaches used? What methods and activities have enabled children, their families, and carers to participate in research informing the development of health resources or interventions designed for children and adolescents? And what factors have influenced their participation? A majority focus on neurotypical children has been found within the literature, thus a secondary aim of this review was to synthesize information on these topics pertaining to children and adolescents who have complex developmental needs. Finally, this review focused on research that demonstrated an authentic level of participation by using Hart's Participation Ladder to identify and exclude papers where participation was deemed perfunctory (level 3 or below).

\section{Materials and Methods}

The protocol for this systematic review was registered with PROSPERO (CRD42020189632). The protocol for review, which includes the research questions, detailed methods and 
planned analyses for the review, can be accessed at the following URL: https://www.crd.york.ac.uk/prospero/display_ record.php?RecordID $=189632$ The methods and findings are reported using the PRISMA 2020 statement as a guide (Page et al., 2021).

\section{Databases Searches and Search Strategy}

A systematic search of peer reviewed literature was carried out in January 2021 on the following databases: Academic Search Complete - via Ebscohost, CINAHL - via Ebscohost, Emcare - via Ovid, Proquest Theses and Dissertations, Pubmed and Google Scholar (Appendix 1). Key search terms and subject headings employed in the search related to participatory approach and the relevant population, included variations of the following terms: participatory design, coproduction, co-design, co-creation, consumer participation, families, child, parent, carer, well-being, quality of life, physical activity. The reviewer who conducted the searches (TB: librarian) adjusted the search for each database. The reviewers also checked the reference lists of included studies to identify additional research, potentially eligible studies.

\section{Selection of Studies}

The identified citations from all the searches were uploaded to EndNote X9 (Clarivate Analytics, 2013) and duplicates removed. The title and abstract of each report were then screened by one reviewer against the inclusion and exclusion criteria (Table 1) and those articles that were clearly ineligible were removed from further consideration. Reports that were potentially eligible were retained for full text review. Full text review of all potentially eligible reports was independently completed by two reviewers, who noted reasons for subsequent ineligibility of any articles and recorded decisions on a spreadsheet. Disagreements were resolved by a third reviewer and ineligible reports were once again removed from further consideration. Two reviewers then independently screened each retained study's participatory approach using Hart's Participation Ladder (Hart, 1997). Only studies involving participatory approaches that were adjudged level 4 or above on Hart's Participation Ladder were included in the systematic review, and again, any disagreements in the assessment of the initial two independent reviewers were resolved by a third reviewer.

\section{Assessments of Methodological Quality}

The Mixed Methods Appraisal Tool (MMAT) was used to appraise the methodological quality of the included studies because it was developed to enable the assessment of five different categories of study designs in a single tool (Hong et al., 2018). In the MMAT each study's methodology is evaluated against five criteria, and the specific criteria differ between study designs. Two reviewers independently scored each study using the MMAT and disagreements were resolved by a third reviewer. As recommended by the MMAT authors, no study was excluded from the review based upon their MMAT score (Hong et al., 2018).

Following appraisal with the MMAT, an assessment of the sufficiency of description of the participatory approach in each included study was completed. A checklist (Table 2) was developed for this purpose, based upon two established checklists for intervention descriptions: The TIDieR checklist (Hoffman et al., 2014) and The CONSORT statement for non-pharmacological interventions (Boutron et al., 2008). The purpose of these checklists is to assist researchers to describe their interventions sufficiently to enable replication. Despite not being quality checklists per se, these checklists can provide the reader with information that allows them to make informed decisions about the adequacy of reporting of the participatory approach, which may in turn provide insights and learnings for future studies (Eyles et al., 2016). The checklist (Table 2) was scored as 'yes', 'limited' or 'no', with 'limited' included as a scoring option in order to provide greater granularity in the results, particularly as a considerable number of studies provided some information but not enough to warrant a clear 'yes' score. Details of the

Table 1 Study eligibility criteria

\begin{tabular}{|c|c|}
\hline Inclusion criteria & Exclusion criteria \\
\hline $\begin{array}{l}\text { 1. Studies which included children and adolescents aged } 3-18 \text { years } \\
\text { and/or their families (including extended families, for example } \\
\text { grandparents, aunts, uncles) or carers }\end{array}$ & $\begin{array}{l}\text { Studies which included families with children }<3 \text { years of age } \\
\text { Studies involving adults without children aged } 3-18 \text { years }\end{array}$ \\
\hline 2.. Provided a description of the participatory approach employed & No description provided of the participatory approach \\
\hline $\begin{array}{l}\text { 3. Used a participatory approach to develop, and in some cases evalu- } \\
\text { ate, a health intervention or resource for children or adolescents }\end{array}$ & $\begin{array}{l}\text { Did not use a participatory approach to develop a health intervention or } \\
\text { resource }\end{array}$ \\
\hline 4. Published between 2000 and 2021 & Research published outside the stated publication period \\
\hline 5. English language publication & Publication in languages other than English \\
\hline $\begin{array}{l}\text { 6. Peer reviewed published research including quantitative, qualitative, } \\
\text { and mixed methods studies }\end{array}$ & $\begin{array}{l}\text { Review articles, theses, conference proceedings and posters, non- peer } \\
\text { reviewed research (including grey literature and opinion papers) }\end{array}$ \\
\hline
\end{tabular}


Table 2 Checklist for sufficiency of reporting of the participatory approach

\begin{tabular}{|c|c|}
\hline Checklist item & Notes on item \\
\hline 1. Is the intention behind the participatory approach described? & $\mathrm{Y}$ or $\mathrm{N}$ \\
\hline 2. Is there a description of where the participatory approach took place? & $\begin{array}{l}\text { Y: provided details of community or named geographical area and } \\
\text { details on where the participatory approach took place (e.g. school, } \\
\text { hospital). L: provided details of only one of these elements. N: not } \\
\text { reported }\end{array}$ \\
\hline 3. Is there a description of who facilitated the participatory approach? & $\begin{array}{l}\text { Y: facilitators described in more detail than 'authors' or 'researchers' } \\
\text { and their expertise/experience was noted. L: facilitators described } \\
\text { but not their expertise/experience. N: not reported }\end{array}$ \\
\hline $\begin{array}{l}\text { 4. Is there a description of who was involved in the participatory } \\
\text { approach? }\end{array}$ & $\begin{array}{l}\text { Y: information on number of co-researchers, their characteristics, } \\
\text { recruitment (and training, if relevant). L: some but not all informa- } \\
\text { tion provided. N: not reported }\end{array}$ \\
\hline $\begin{array}{l}\text { 5. Is a description of the intervention or resource that was developed } \\
\text { provided? }\end{array}$ & $\begin{array}{l}\text { Y: relevant details reported. L: missing some relevant details. N: not } \\
\text { reported }\end{array}$ \\
\hline $\begin{array}{l}\text { 6. Are descriptions of the phases and methods of participatory approach } \\
\text { provided? }\end{array}$ & $\begin{array}{l}\text { Y: information on both the methods used, phases (if relevant) and } \\
\text { activities all reported. L: some but not all information provided. N: } \\
\text { not reported }\end{array}$ \\
\hline $\begin{array}{l}\text { 7. Are descriptions of the intensity and schedule of the participatory } \\
\text { approach provided? }\end{array}$ & Y: relevant details reported. L: missing some detail. N: not reported \\
\hline 8. Is the intention of participatory approach evaluated? & $\mathrm{Y}$ or $\mathrm{N}$ \\
\hline
\end{tabular}

$Y$ yes, $L$ limited, $N$ no

criteria underpinning each score are noted in Table 2. The total score was calculated by allocating a score of one to the 'yes' answers, 0.5 to 'limited' answers, and zero to 'no' answers. Two reviewers independently scored each study using the checklist. No study was excluded from the review based upon their sufficiency of reporting of the participatory approach rating.

A Spearman's Rank Correlation coefficient was calculated to assess the relationship between study MMAT total scores and the total scores for sufficiency of reporting of the participatory approach.

\section{Data Extraction}

The following data were extracted from each included study and documented in standardised tables to ensure that all outcomes of the review were addressed: authors, publication year, title of study, country, author identified study design, setting, facilitators, co-researchers (families/carers of children), co-researchers (children), intervention or resource developed, description of participatory approach methods and phases, intensity and schedule of participatory approach, factors that influenced participatory approach, level of shared-decision-making involved in the participatory approach, participatory approach evaluated status, and other findings relevant to the aims of the review. Piloting of the data extraction table was completed to ensure consistency within and between reviewer, across the elements to be extracted. Two reviewers extracted the data separately and then the data were combined by one reviewer, in consultation with other reviewers to clarify and confirm the data to be tabulated, where needed.

\section{Synthesis}

A critical narrative approach was taken to synthesize key findings from the included studies. Meta-analysis was not conducted as the included studies were not sufficiently homogenous to allow for this. The consideration of findings from individual studies in the synthesis was guided by the results of the MMAT quality screening and the checklist for sufficiency of reporting of the participatory approach. Content analysis, as described by Hsich and Shannon (2005), was used to analyse some elements of the extracted data. The analysis generated a catalogue of key words and phrases from which central categories were identified and integrated with the overall synthesis of key findings.

\section{Results}

\section{Identification and Selection of Studies}

The PRISMA flow diagram in Fig. 1 summarizes the results of the processes employed to identify and select studies for inclusion in the review. The search strategy identified 1344 studies for screening after duplicates had been removed. Title and abstract screening resulted in 1072 papers being excluded and the full texts of 272 studies were subsequently 


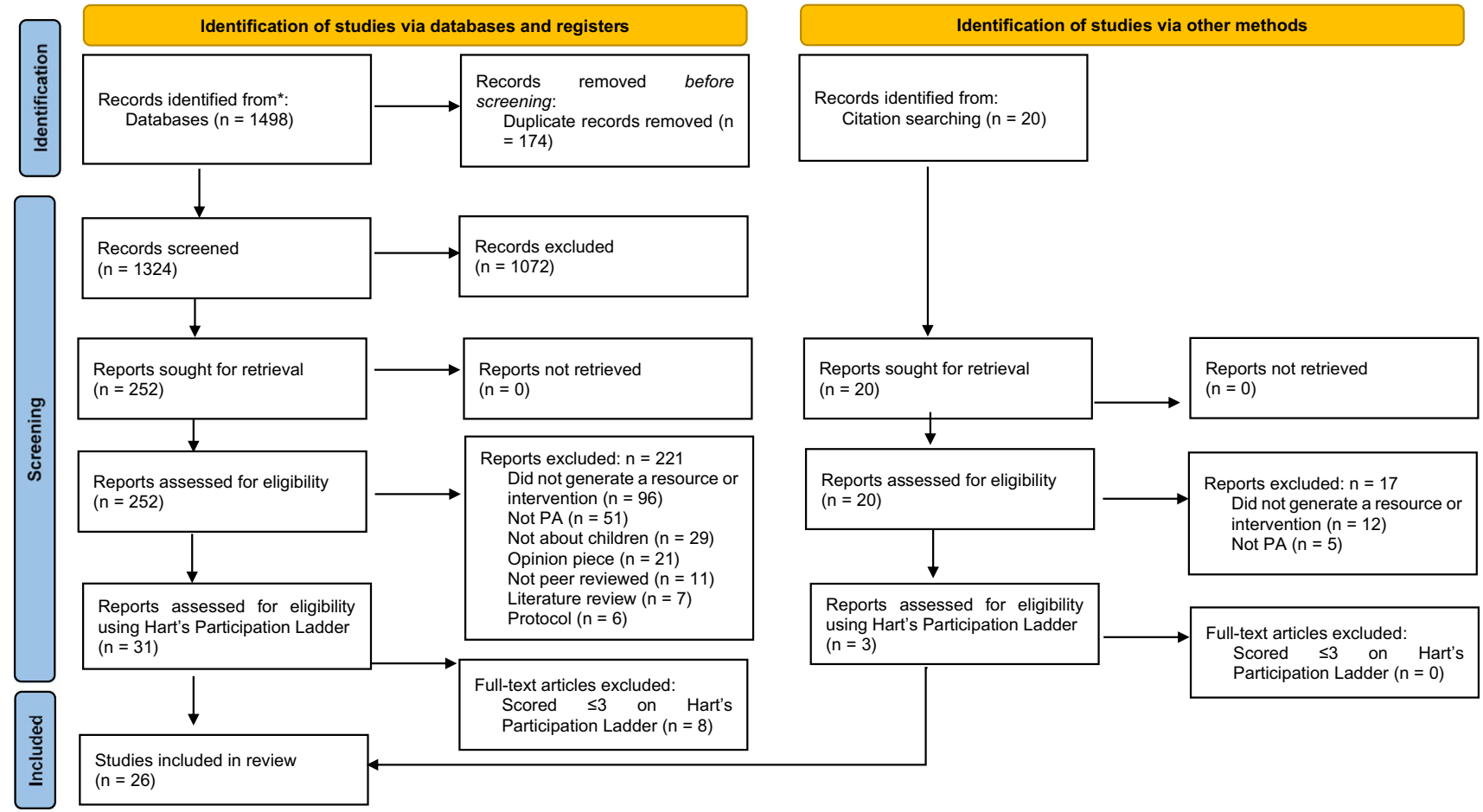

Fig. 1 PRISMA-based flow diagram (Page et al., 2021) depicting literature search, screening and selection processes

obtained for review. Two hundred and thirty-eight of those studies were excluded in part 1 of the full text review process. The remaining 34 studies were then assessed for their level of co-researcher participation against Hart's Participation Ladder (Hart, 1997), which resulted in a further eight studies being excluded. Thus, 26 studies were included in the review.

\section{Characteristics of Included Studies}

The characteristics of the 26 included studies are collated in Table 3. All but two of the studies (Hussain, 2010; Ruland et al., 2008) were from the second identified decade of the review period (2011-2021). The studies originated from eight countries, with over half of the studies from two countries (USA $n=9$, UK $n=6$ ). Authors described a wide variety of participatory approaches utilized including community-based participatory research $(n=6)$, codesign $(n=4)$, participatory design $(n=3)$, coproduction $(n=3)$, user-centred design $(n=3)$, and other types of participatory research $(n=4)$. Two studies did not overtly state their approach (Abrines et al. 2015; Hidding et al., 2020) and thus their apparent approach has been reported in brackets in Table 3 to show it was only indicated; and one study (Carlton, 2013) did not state or indicate an approach. Four broad types of study designs were utilized in the identified studies. No quantitative descriptive studies were utilized in the identified studies. Nearly three quarters of the studies $(73 \%$, $\mathrm{n}=19)$ used a qualitative research design, three (12\%) were quantitative in design (randomised controlled trial $n=1$, and non-randomised controlled trial $\mathrm{n}=2)$; and four $(15 \%)$ used a mixed method design. Ten studies (38\%) gained access to some or all their co-researchers at schools, with four of those studies using multiple schools. Other settings included: hospitals $(n=6)$, community settings such as a community resource centre or YMCA facility $(n=5)$, community health settings $(n=3)$ and at the participant's home $(n=1)$. Four studies used two or more different settings, such as a local school and paediatric hospital, to limit the burden of the research on children with medical conditions. Six studies provided only a broad geographical location or descriptor (e.g. local health service or health region) rather than reporting more specific physical settings like those described above.

Most studies $(88 \%, \mathrm{n}=23)$ involved children or adolescents as co-researchers (age range: 3 to 17 years), sometimes alongside family, carers, and other types of co-researchers, discussed below. The other three studies involved no children but involved mothers (Biediger-Friedman et al., 2016; Mammen et al., 2019), parents and guardians (Hardt et al., 2020) and other community stakeholders such as cultural advisors and health professionals (Hardt et al., 2020; Mammen et al., 2019) as co-researchers. Thirteen studies (50\%) involved children or adolescents as the sole co-researchers (apart from the study authors); more specifically, seven studies $(27 \%)$ involved adolescents as the sole co-researchers, 


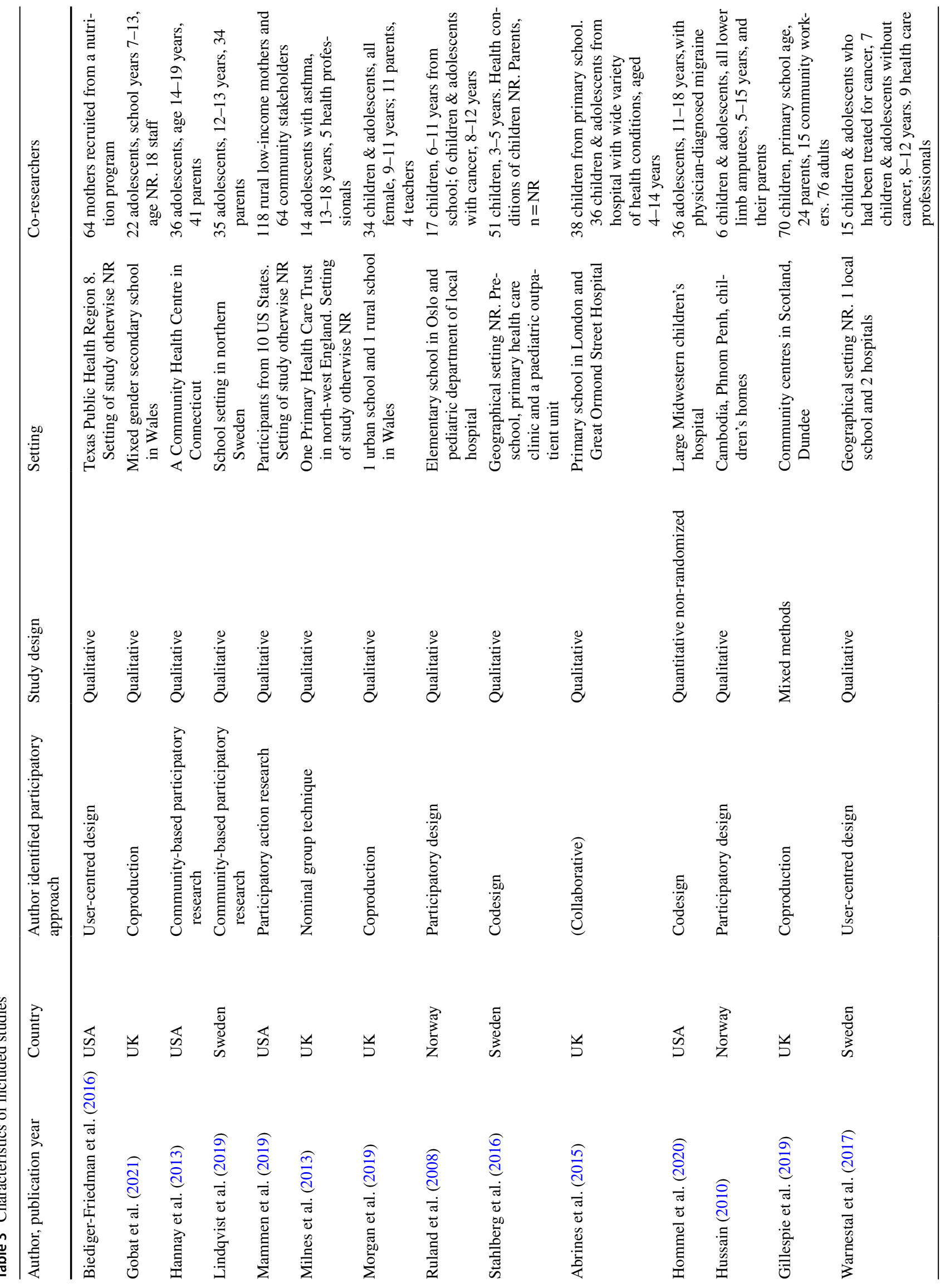




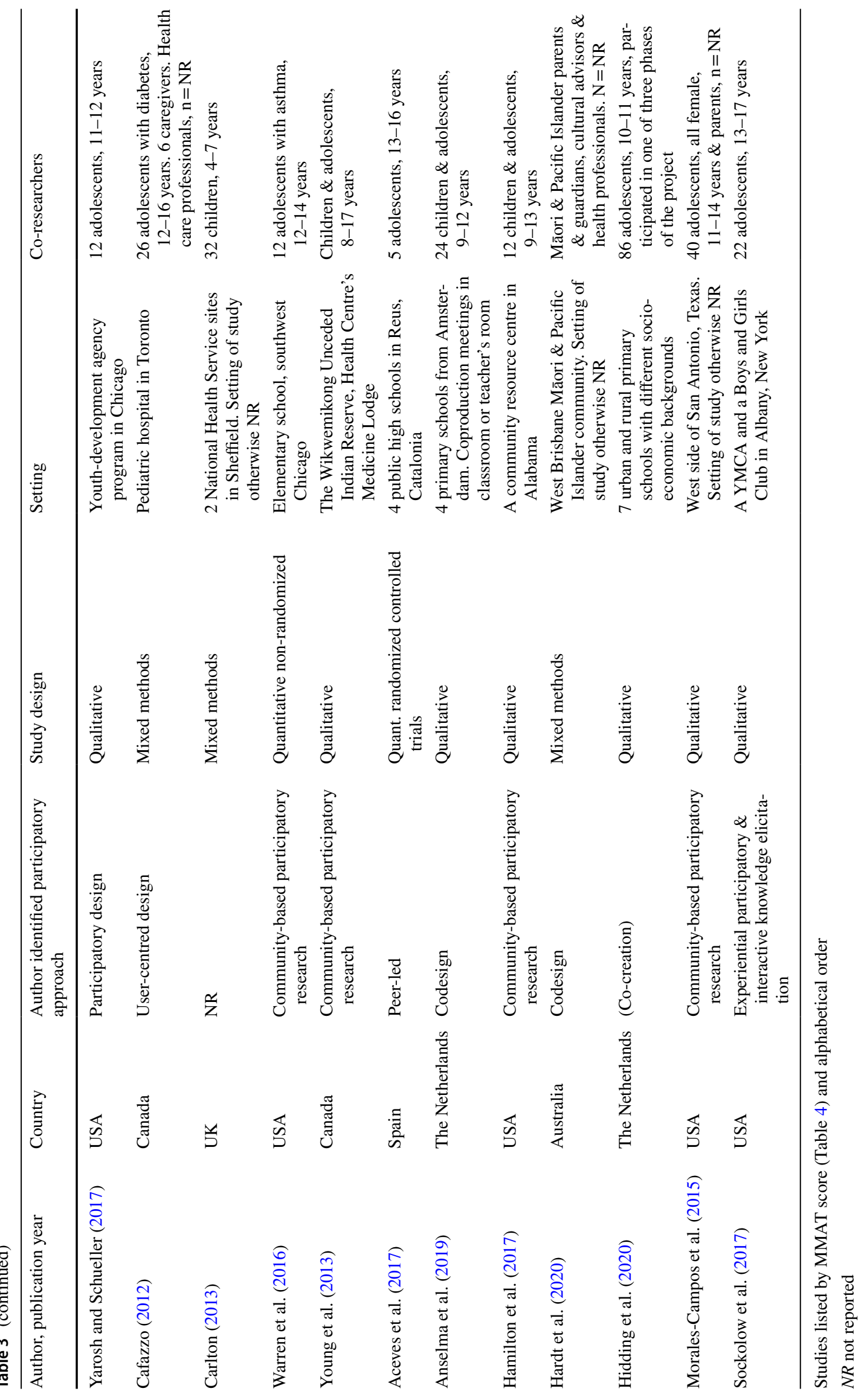


five studies (19\%) involved both children and adolescents as the only co-researchers, whilst only one study (Carlton, 2013) involved children aged 4-7 years as the sole coresearchers. Eleven of the studies (42\%) included children or adolescents with medical conditions or physical disabilities as co-researchers. Medical conditions included: amblyopia, amputation, cancer, diabetes, and migraine. Four studies (15\%) included pre-school aged children as co-researchers (Abrines et al., 2015: 4-14 years; Carlton, 2013: 4-7 years; Hussain, 2010: 5-15 years; Stahlberg et al. 2016: 3-5 years). No studies were found which involved children who were not meeting developmental milestones as co-researchers. Adult co-researchers involved in 13 of the included studies included parents or caregivers $(42 \%, \mathrm{n}=11)$, health professionals $(15 \%, n=4)$, community stakeholders $(n=3)$ and teachers $(n=2)$.

\section{Methodological Quality}

Nine of the twenty-six studies (35\%) met all five of the MMAT quality criteria associated with the respective research design (Table 4); all these nine used a qualitative methodology. A further six studies (23\%) met four of the quality criteria. All the included qualitative studies $(n=19)$ were judged to have met the MMAT criteria for their approach and data collection methods. However, the findings were not adequately derived from the data in seven of the qualitative studies, eight did not report adequate data to substantiate their results and six did not show coherence between their data sources, collection, analysis, and interpretation. Neither of the two included quantitative non-randomized studies adequately accounted for confounders in their design and analysis; and three quarters of the mixed method studies $(\mathrm{n}=3)$ did not explain inconsistencies between the findings of each method in their synthesis or show sufficient quality across both qualitative and quantitative components of the mixed method study.

The findings from assessment of the sufficiency of reporting of the participatory approach used in each study are shown in Table 4 alongside the MMAT results. In summary, no studies fully met all eight of the criteria, but nine studies $(35 \%)$ fully met between five and seven of the criteria. Most studies (88\%) stated their intentions behind the use of a participatory approach however, only four studies (15\%) evaluated their stated intentions. All studies reported some characteristics of the setting for the participatory approach, however in nearly a third of the studies (31\%) the information provided was limited. Likewise, all studies reported some characteristics of the co-researchers but in $54 \%$ of studies the reporting was limited. Most studies provided sufficient to limited reporting of interventions (sufficient: $65 \%$ ) and methods and phases of the participatory approach (sufficient: $81 \%$ ). The reporting of people who facilitated the participatory approach, and the intensity and schedule of the participatory approach were more varied across the studies. Just over half $(54 \%)$ of studies reported who facilitated the participatory approach and half the studies $(50 \%)$ reported sufficiently on the intensity and schedule of their participatory approach. Less than half (42\%) of studies provided sufficient descriptions of both methods, and intensity and schedule of the participatory approach.

The Spearman's rank-order correlation assessing the relationship between the methodological quality of the studies and the sufficiency of reporting of the participatory approach found no correlation between MMAT scores and sufficiency of reporting of the participatory approach $\left(\mathrm{r}_{\mathrm{s}}=-0.18\right.$, $\mathrm{p}=0.37$ ). Three studies (11\%) (Hannay et al., 2013; Ruland et al., 2008; Yarosh \& Schueller, 2017) scored highly on both the MMAT $(\geq 4)$ and on the sufficiency of reporting of the participatory approach $(\geq 6)$.

\section{Characteristics of Participatory Approaches}

Table 5 summarizes the characteristics of participatory approach employed in the included studies. Four studies $(15 \%)$ reported frameworks that were used to inform design of their participatory approach. Two frameworks were used to provide a systematic approach to engaging with communities: The Analysis Grid for Environments Linked to Obesity (ANGELO) (Gillespie et al., 2019) and Intervention Mapping (Anselma et al., 2019). Milnes et al. (2013) used a health behaviour change model (Health Action Research Approach, Schwarzer, 2008) to support their development of a pre-consultation guide for adolescents with asthma. Hardt et al. (2020) were guided by a cultural framework for researchers, Te Ara Tikka (Hudson et al., 2010), together with Māori and Pacific Islander researchers, to steer their development of a childhood obesity prevention program tailored to Māori and Pacific Islander cultures in Australia.

The content analysis of relevant extracted data identified six stages in which co-researchers participated in the development of an intervention or resource (Table 5). Definitions of these stages are provided in Table 6 . Refining $(n=n=21$, $81 \%)$, ideating $(n=20,77 \%)$ and creating $(n=18,69 \%)$ were the most common stages of intervention or resource development in which co-researchers participated. Co-researchers contributed less frequently to the implementing $(n=3$, $12 \%)$, sharing $(n=3,12 \%)$ and evaluating $(n=1,4 \%)$ stages of intervention or resource development. Out of the four studies that engaged pre-school children as co-researchers (Abrines et al. 2015; Carlton, 2013; Hussain, 2010; Stalberg et al. 2016), all employed co-researchers in the refining stage $(n=4)$, and two studies involved co-researchers in the ideating (Carlton, 2013; Hussain, 2010) and creating 


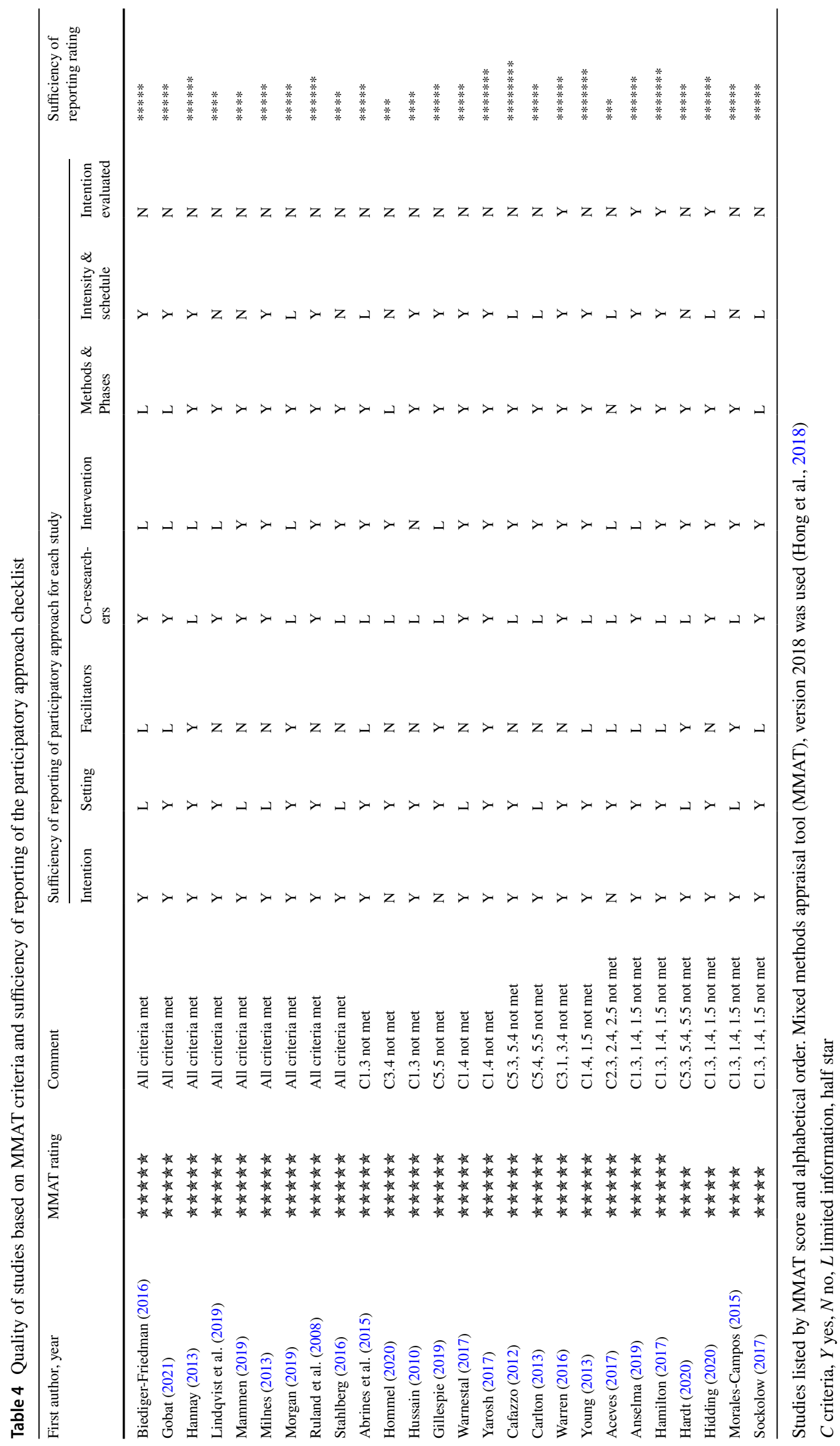




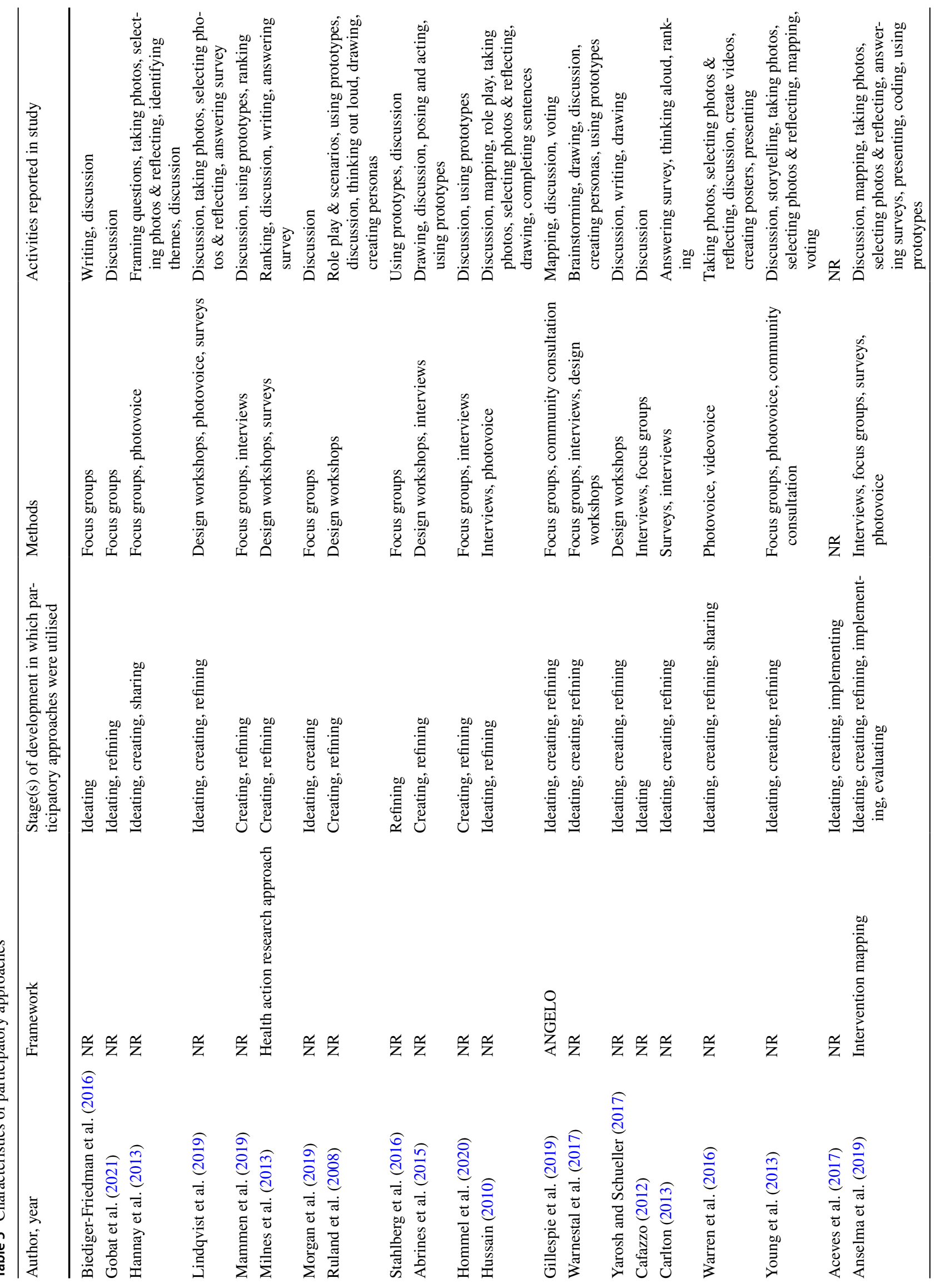


(Abrines et al. 2015; Carlton, 2013) stages of the intervention or resource development, respectively.

Seven different methods were identified as forming part of the participatory approach utilized by the included studies, with more than half of the studies using focus groups $(\mathrm{n}=15,58 \%)$ as part of their participatory approach (Table 5). The other methods utilized were interviews $(\mathrm{n}=10,38 \%)$, photovoice $(\mathrm{n}=9,35 \%)$, design workshops ( $n=8,31 \%)$, surveys $(n=6,23 \%)$, community consultations $(\mathrm{n}=3,11 \%)$ and videovoice $(\mathrm{n}=1)$. One study provided no information on the methods utilized in their participatory approach (Aceves et al. 2017). Nineteen studies (73\%) used multiple methods as part of their participatory approach and five of the remaining studies (19\%) used the same method over multiple phases.

The structures of the methods summarized above were then examined further to determine the kinds of activities that authors reported took place within each method (Table 5). Most studies $(n=22,85 \%)$ used multiple activities as part of their participatory approach. Table 7 maps these activities against the methods to allow further comparison between the methods and their compositions. Discussion was used as an activity within all method types except for surveys. In addition, some activities were unique to a particular method. For example, taking photos was only utilized as part of a photovoice method.

\section{Reported Factors That Influenced Engagement in the Participatory Approach}

Categories were identified from a content analysis of reported enablers and barriers to engaging in the participatory approaches. Three categories of enablers were reported by ten authors (38\%) and four categories of barriers were reported by eleven authors (42\%). Table 8 shows each category, the number of authors who identified items in each category and key examples of items within each category (please note that some authors identified items in more than one category).

\section{Shared Decision Making}

Eighteen authors (69\%) commented on shared decision making during the participatory approaches. These comments were grouped by content analysis into five categories shown in Table 9.

\section{End User Input Into Final Resource}

Thirteen authors (50\%) reported on end user input into the final resource or intervention produced. Nine authors provided a description of where co-researchers gave their input into the final resource or intervention. For example, 
Table 6 Definitions of the stages of development of interventions or resources in which a participatory approach was utilized

\begin{tabular}{ll}
\hline Stage of PA & Definition \\
\hline Ideating & Co-researchers participated by giving their opinion and sharing their experiences of a topic related to an intervention or resource \\
Creating & Co- researchers participated by generating suggestions or designing aspects of an intervention or resource \\
Refining & Co-researchers participated by refining and improving aspects of an intervention or resource prototype \\
Implementing & $\begin{array}{l}\text { Co-researchers participated by implementing an intervention or health resource. (N.B. this is different to being a participant in } \\
\text { an intervention or using a health resource) }\end{array}$ \\
$\begin{array}{l}\text { Evaluating } \\
\text { Co-researchers participated in co-producing an evaluation of an intervention or health resource }\end{array}$ \\
Sharing & Co-researchers participated by helping to disseminate an intervention or health resource \\
\hline
\end{tabular}

Table 7 Mapping of activities against methods utilized in participatory approaches

\begin{tabular}{|c|c|c|c|c|c|c|c|}
\hline \multirow[t]{2}{*}{ Activity } & \multicolumn{7}{|l|}{ Method } \\
\hline & $\begin{array}{l}\text { Community } \\
\text { consultations }\end{array}$ & $\begin{array}{l}\text { Design } \\
\text { workshops }\end{array}$ & Focus Groups & Interviews & Photovoice & Surveys & Videovoice \\
\hline Answering surveys & & & & & & $\checkmark$ & \\
\hline Brainstorming & & & $\checkmark$ & & & & \\
\hline Coding & & & & $\checkmark$ & & & \\
\hline Completing sentences & $\checkmark$ & $\checkmark$ & & $\checkmark$ & $\checkmark$ & & $\checkmark$ \\
\hline Creating personas & & $\checkmark$ & $\checkmark$ & $\checkmark$ & & & \\
\hline Discussion & & $\checkmark$ & & & & & \\
\hline Drawing & & & & & & & \\
\hline Framing questions & & & $\checkmark$ & & & & \\
\hline Identifying themes & & & $\checkmark$ & & & & \\
\hline Mapping & & $\checkmark$ & $\checkmark$ & $\checkmark$ & & & \\
\hline Posing & & $\checkmark$ & & & & & \\
\hline Presenting & & $\checkmark$ & $\checkmark$ & & & & \\
\hline Ranking & & $\checkmark$ & $\checkmark$ & $\checkmark$ & & & \\
\hline Role play & & $\checkmark$ & $\checkmark$ & $\checkmark$ & & & \\
\hline Select \& reflect on photos & & & & & $\checkmark$ & & $\checkmark$ \\
\hline Storytelling & & & $\checkmark$ & & & & \\
\hline Taking photos/videos & & & & & $\checkmark$ & & $\checkmark$ \\
\hline Thinking aloud & & $\checkmark$ & & $\checkmark$ & & & \\
\hline Using prototypes & & $\checkmark$ & $\checkmark$ & $\checkmark$ & & & \\
\hline Voting & $\checkmark$ & $\checkmark$ & & & & & \\
\hline Writing & & $\checkmark$ & $\checkmark$ & & & & \\
\hline
\end{tabular}

Gillespie et al. (2019) reported that co-researchers provided input into priority list of interventions but not the content of the subsequent interventions. Two authors provided specific examples of end user ideas that were used in the intervention in the results section of their paper (Lindqvist et al. 2019; Milnes et al. 2013). Another two authors counted the numbers of ideas that co-researchers contributed during the participatory approach (Ruland et al., 2008; Yarosh \& Schueller, 2017).

\section{Child and Adolescent Development}

It is notable that the despite the wide age range of the child and adolescent co-researchers found in this review, and sometimes within a single included study, it appears as though little attention was paid to the developmental level of the child and adolescent co-researchers beyond their age or school level. Some authors grouped co-researchers into younger and older age groups, but this appeared to be for convenience, utilizing school years or particular groups, rather than an intentional developmental approach as authors did not report adapting the activities or methods between these groupings to address developmental differences or 
Table 8 Categories and examples of reported factors that influenced engagement in the participatory approaches

Logistic enablers $(n=7)$

Keep activities short and entertaining (Abrines et al., 2015)

Greater interaction between co-researchers when working in pairs or single gender groups (Ruland et al., 2008)

Collaboration enablers $(n=5)$

Researchers should be flexible in their engagement to allow co-researchers to lead when able (Anselma et al., 2019)

Use facilitators, who have prior relationships with co-researchers, to assist discussion of sensitive topics (Sockolow et al., 2017)

Activity enablers $(n=4)$

Use role play and scenarios to enable healthy co-researchers to imagine living with a serious illness (Ruland et al., 2008)

Foster creativity by allowing co-researchers to brainstorm ideas without considering practicalities (Anselma et al., 2019)

Logistic barriers $(n=5)$

Short timelines can affect ability of co-researcher's participation (Mammen et al., 2019)

Difficult to estimate duration of steps in participatory approach as co-researcher's cognitive ability unclear (Anselma et al., 2019)

Engagement barriers $(\mathrm{n}=11)$

Co-researchers reading ability and understanding of a ranking task impacted their engagement (Carlton, 2013)

Important to manage co-researcher's expectations as it can affect their engagement (Abrines et al., 2015)

Power imbalance barriers $(\mathrm{n}=2)$

Using webcams for video data collection process which distracted co-researchers \& amplified the power differential (Yarosh \& Schueller, 2017)

Ethical barriers $(n=1)$

Ethical issues related to burden on co-researchers who have an illness (Ruland et al., 2008)

Table 9 Categories and examples of author comments on shared decision-making

Extent of shared decision making $(\mathrm{n}=9)$

Adolescent co-researchers provided suggestions and commented on researchers prototypes but no overt shared decision-making (Sockolow et al., 2017)

Content of videos and posters involved shared decision making (Warren et al., 2016)

Types of shared decision making $(n=3)$

Pre-school child co-researchers alternated between tester and informant (Stahlberg et al., 2016)

Typically, informers but sometimes design partners (Ruland et al., 2008)

Co-researcher's role in shared decision making $(n=4)$

Adolescents co-researchers ranked ideas and study reports on highest ranked concepts in results (Milnes et al., 2013)

Child and adolescent co-researchers were encouraged to identify common patterns and themes, and come to a group consensus (Hamilton et al., 2017)

Enablers to shared decision making $(\mathrm{n}=2)$

Prepared adolescent co-researchers by providing them with opportunities to critically reflect as a group, run by trained facilitators, prior to

engaging with community and research co-researchers (Morales-Campos et al., 2015)

Utilised multiple stages to allow co-researchers to reflect upon their previous ideas (Yarosh \& Schueller, 2017)

Obstacles to shared decision making $(\mathrm{n}=2)$

Co-researchers had difficulty reaching full consensus so researchers to made final decisions (Abrines et al., 2015)

Co-researchers limited by their knowledge of psychology, pedagogy \& design (Ruland et al., 2008)

discuss the impact of the different levels of development. In addition, no obvious differences could be discerned between studies in the use of specific activities and methods to accommodate different development levels of children and adolescents. Thus, this review cannot provide insights into participatory approaches employed across child and adolescent developmental levels and acknowledges this as an important gap in the literature.

\section{Discussion}

Research with children and adolescence increasingly use participatory approaches to inform the development of health resources and interventions. This has led to a need for this review. Though the evidence base identified in the review was limited and individual studies were of low or medium methodological quality, the findings nevertheless provide some valuable practical guidance on ways in which participatory approaches have been and can be used to collaborate in research with children and their families. The findings also highlight some key limitations in participatory approaches employed in such studies to date and indicate 
areas for improvement in future participatory research. The review identified twenty-six studies that have employed, and in some instances evaluated, a participatory approach engaging children, families, and carers in research conducted to inform development of health resources or interventions. Across these studies, child and adolescent co-researchers were mostly involved in participatory approaches at earlier stages of resource or intervention development, and involvement in the later stages of resource or intervention development was rare. Furthermore, little consideration was evident in the studies of the developmental stage of the child coresearchers, and approaches were not explicitly adjusted for this factor.

Findings from this review about how participatory approaches have been used with children and families may be used to guide practice. A wide variety of participatory approaches were identified, including approaches termed community-based participatory research, co-design, participatory design, coproduction, and user-centred design. Although nearly three quarters of the included studies used a qualitative research design, studies that involved participatory approaches have also been utilised in quantitative and mixed method research designs. Schools and health settings were the most frequently used settings in which participatory approaches with children, adolescents, and their families were implemented. Only four studies used a framework to guide their study, with those used being either ANGELO (Swinburn et al., 1999) or Intervention Mapping (Bartholomew et al., 1998). It seems reasonable that using a framework to provide structure to a participatory approach might improve the quality of the studies and participatory approach, including engagement of co-researchers during more stages of development and the reporting of the study. But the small number of studies that used a framework in this review do not allow the authors to reach such conclusions. In addition, the authors acknowledge that there may not have been an appropriate framework to draw upon for some studies within their area of practice. This highlights an important gap in the field and the importance of publishing further good quality studies that have used participatory approaches informed by frameworks supported by peer reviewed literature.

Most studies in the review used multiple methods and a wide variety of activities were utilized as part of the methods. The methods used in participatory approaches involving children, adolescents, and families were focus groups, design workshops, interviews, photovoice, surveys, community consultations and videovoice. Twenty-two of the twenty-six included studies used activities other than discussion as a part of their method. The activities employed included brainstorming, drawing, framing questions, identifying themes, mapping, ranking, roleplay and taking photos. Table 7 provides a complete list of activities reported in the studies and may be useful to prompt clinicians and researchers using a participatory approach to consider additional activities. The use of multiple methods and a wide variety of activities is an important strength of studies involving participatory approaches, as it demonstrates efforts by authors to utilize the communication strengths of children. Using familiar and multi-modal means of communication is recommended to gain meaningful insights into a child's world and encourage them to express their opinion (Thomas \& O'Kane, 1998). However, no insights were provided about which methods and activities to use across the different levels of child and adolescent development, as studies used the same methods and activities across their co-researcher population, with no adaptations reported for children at particular developmental stages. The developmental level of the population from which co-researchers are to be drawn, and the individual developmental levels of the co-researchers, should be considered in future studies to ensure that co-researchers are able to authentically engage with the participatory approach, and to build the evidence base for this inclusive approach.

In addition, this review identified six stages in which child and family co-researchers engaged in participatory approaches: ideating, creating, refining, implementing, evaluating, and sharing. These stages can be used to plan engagement of co-researchers throughout the entire development of a health resource or intervention. The review found that co-researchers were more likely to be involved in the earlier stage of development of an intervention or resource and few studies utilized co-researchers in the later stages of intervention or resource development. This finding concurs with findings of another systematic review of methods used to engage children, youth, families, and service providers in mental health service improvement (Mulvale et al., 2016). The finding may reflect a number of factors, including: (1) that this is still a relatively new approach to use with children and adolescents; (2) that earlier stages of research are the easier stages to engage with co-researchers; (3) some studies may not have finished publishing those aspects of their project; and (4) practical aspects of conducting a participatory approach, such as the amount of time required to engage with children and adolescents or challenges with gaining repeated access to populations over long periods of time (Mammen et al., 2019). Nonetheless, it does suggest that the co-researchers' influence may have been limited in some of the studies, and this may have impacted upon the potential of the developed intervention or resource to respond to the needs of the end-user. This finding is disappointing, because tailoring the intervention or resource to the needs of the end-user was the stated purpose behind using a participatory approach, in many of the included studies.

Other findings from this review that may guide practice, for example, reporting of shared decision-making, are considered in subsequent sections of this discussion. It should 
be acknowledged that whilst these findings provide useful examples of previous used participatory approaches, the review found limited analysis indicating evaluation and success of participatory approaches. Thus, these findings should be used cautiously to inform future participatory approach.

This review found there is limited available evidence regarding participatory approach used with children, families and carers to coproduce health resources or interventions and that most of the available evidence is from studies of low or moderate methodological quality. In this review, only three out of twenty-six eligible studies were found to score highly on both aspects of methodological quality (Hannay et al., 2013; Ruland et al., 2008; Yarosh \& Schueller, 2017), relating to research methods (assessed using the MMAT tool) and the sufficiency of reporting of the participatory approach based upon the TIDieR checklist and the CONSORT statement for non-pharmacological interventions. The lack of robust methodological descriptions in most of the included studies makes it difficult for the reader to be confident about the value of the participatory approach. The finding of scarce, good quality peer reviewed literature concurs with findings from previous systematic reviews that have investigated participatory approach both with children (Bradbury-Jones et al., 2018) and with other populations, such as those in receipt of mobile health interventions (Eyles et al., 2016). However, by highlighting some of the issues found in the literature thus far, this review may help inform future higher quality studies.

None of the available studies included children or adolescents who had been identified as having complex developmental needs, or their families, as co-researchers. Interventions for these populations have been found to improve their development, for example motor skills training (Preston et al., 2017), but they have been health researcher-led interventions. In addition, regular physical activity has been identified as an important ongoing management strategy for children and adolescents with some developmental disorders such as ADHD (Den Heijer et al., 2016). Using a participatory approach to enhance what has already been shown to help may result in more targeted and acceptable interventions or resources for these populations (McLaughlin, 2006) and increase the sustainability of their outcomes (Hill, 2006), which is an important consideration for long term interventions. Eleven of the studies in this review included children or adolescents with medical conditions as co-researchers, including studies pertaining to the management of asthma (Milnes et al. 2013; Warren et al. 2016), diabetes (Cafazzo et al., 2012), and migraine (Hommel et al., 2020) (Table 3). This shows that participatory approaches are gradually being used with children and adolescents who might be deemed "vulnerable", but more can still be done to ensure that those children and adolescents who are vulnerable are given a voice (Bradbury-Jones et al., 2018).
Evidence of the involvement of co-researchers in participatory approach was limited. Only half of the studies reported end user input into the final intervention or resource. Content analysis of the data extracted from included studies found that there were three different ways authors presented information on end user input. These may provide examples to other researchers and included: providing a description of where co-researchers provided input; providing specific examples of end user input that was incorporated into the invention or resource; and counting the number of ideas generated by co-researchers that were included in the intervention or resource. But some of these examples may lend themselves to a particular participatory approach better than others. For example, counting the number of ideas that co-researchers contribute to a prototype (Ruland et al., 2008; Yarosh \& Schueller, 2017) might not be feasible in every context but providing examples of end user ideas that were incorporated into an intervention or resource should be possible with all participatory approach. Likewise, reporting on factors that impacted the participatory approach was low, with less than half of authors reporting any enablers and barriers they encountered. These included: logistic, collaboration and activity enablers; and logistic, engagement, power imbalance and ethical barriers (Table 8). These types of enablers and barriers have all been identified in previous literature as factors affecting engagement with children in research (Montreuil et al., 2021; Mulvale et al., 2016). Some authors provided solutions to the barriers they encountered. For example, Yarosh and Schueller (2017) found that using webcams to collect video data increased the power differential between them and the co-researchers and distracted the co-researchers from their tasks. They reported that they reduced the impact of these issues by asking the co-researchers to use the webcams to record their ideas themselves, which increased co-researchers' control and engagement. Authors should be encouraged to describe both the factors that impact their participatory approach and any solutions that they instigate, because such factors impact the intervention or action-facilitating aspect of a participatory approach. The 2017 CONSORT checklist for reporting of non-pharmacological interventions recommends that authors provide details on "how adherence of participants to intervention was assessed or enhanced" (Boutron et al., 2017). While 'adherence' is not part of the ethos of participatory approaches, from a reporting perspective, describing factors that affected engagement in participatory approach is arguably the participatory approach equivalent of describing factors that impacted adherence to an intervention. Eighteen authors (69\%) commented on shared decision making with co-researchers during their participatory approach and themes were grouped by content analysis into five categories: extent, types, co-researcher's role, enablers, and obstacles to shared decision making. This shows that there are 
several different ways in which authors can consider and report shared decision making. It was disappointing that more authors did not address this aspect of participatory approach, given that engaging in research with people is the key attribute of using a participatory approach, and the authors contend that those studies that have not reported on shared decision making are not providing sufficient evidence of using a participatory approach. A better description of how co-researchers were involved in shared decision making would provide a greater understanding of how much the planned methodology was adapted to the context during the project, which should be an expected part of using a participatory approach. Good descriptions provide additional insights and evidence of participatory approach in the messy domain of participatory research; however, it should be acknowledged that providing these insights is also influenced by the real-world issues of limited word counts for publications.

As previously stated, few studies met both aspects of methodological quality: low risk of bias, reflected in MMAT scores, and sufficiency of reporting, reflected in scores on a checklist. A large range in quality of studies was found using the MMAT, with only half of the included studies meeting four or more of the five criteria. Thus, caution should be applied in drawing conclusions from their findings. The checklist for the sufficiency of reporting of the participatory approach found that many authors provided limited or no information on the setting, facilitators, characteristics of co-researchers (number, gender, age, experience), and intensity and schedule of the participatory approach; and only four studies evaluated their stated intentions for their participatory approach. These omissions mean that the reader would be unable to judge if the authors' claims of co-researcher engagement were valid. However, a strength of the included studies was that the intention, setting, and codesign methods were mostly sufficiently reported. It is important to again acknowledge the difficulties that many of these papers may encounter in publishing papers including a participatory approach within word count limits. Most of the papers included qualitative or mixed method designs, which meant they would need to use a greater proportion of available words in the results section to ensure they are providing adequate evidence of findings, although this was also found to be lacking in nearly half of the qualitative studies. Journals that wish to publish participatory research papers with good quality methods and findings sections should consider increasing allowed word counts for such papers.

This review highlights the need for dedicated reporting guidelines to encourage author's claims to be grounded in research data and ensure that reporting of the participatory approach is sufficient. Eyles et al. (2016) has also noted the difficulties in assessing participatory approaches in systematic reviews and suggested that a checklist specific to participatory approaches should be developed. Building upon this suggestion, the authors recommend that both aspects of research involving a participatory approachassessment of risk of bias inherent in the research methods, as well as the participatory approach—warrant focus by papers describing participatory approaches and systematic reviews of participatory approaches in research. The dilemma is whether these can reasonably be incorporated into one checklist or whether the risk of bias and participatory approach aspects should be addressed by two different tools. There are already many good, peer reviewed methodological appraisal tools to choose from. This review found the MMAT's ability to accommodate five different categories of study designs to be ideal for purpose, but the authors acknowledge that subsequent reviews may have different criteria which influence their choice of methodological quality assessment tool. A subsequent iteration of the sufficiency of reporting checklist used in this review (Appendix 2) may be useful for assessing participatory approaches, with two additional items: shared decision making, and end user input into the final resource or intervention. These items would be useful catalysts to increase the description and evidence for participatory elements of the participatory approach. In addition, the six stages identified in this review, where child and family co-researchers could participate in the development of resources and interventions, might be used to plan and assess the level of co-researcher involvement throughout the development of a health resource or intervention. Reaching a consensus on how checklists and quality tools are combined, to inform the overall quality of participatory approaches, through the development of reporting guidelines, would enhance the quality of future participatory research projects by providing greater direction to researchers.

A strength of this review is that it is the first review to map the frameworks, methods and activities used in research to enable children, families, and carers to be involved in a participatory approach designed to support development of health resources or interventions. Thus, this review provides useful, practical insights into how researchers are using a participatory approach with these populations. Two tools, the MMAT and a checklist of sufficiency of reporting of the participatory approach, were used to inform the review. Adequate reporting of the participatory approach is important for studies using these approaches, as it permits readers to judge the quality of the participatory approach and enables replication of successful methods and activities. The sufficiency of reporting checklist was developed for this review, based upon two previous checklists for sufficiency of reporting of interventions (Boutron et al., 2008; Hoffman et al., 2014). However, the authors acknowledge that, unlike some interventions, such as medication interventions, exact replication is not a desirable aim for participatory approaches in research where researchers are seeking to 
adapt their approaches to the unique populations with which they are working.

Limitations of this review include that the studies were limited to those published in English and that the generally poor quality of the included studies limited conclusions that could be drawn from the review.

\section{Conclusion}

To address the limited evidence base for the use of participatory approaches with children and adolescents, a systematic review was undertaken on engaging children and families in research supporting the coproduction of health resources and interventions for children and adolescents. The review provides some practical insights into ways of engaging children and families in participatory approaches within such research. However, available evidence was limited, and the eligible studies were mainly of low or medium methodological quality. Forty-two per cent of studies included children or adolescents with medical conditions or physical disabilities but none of the studies included children and adolescents with complex developmental needs. In addition, no clear insights were found which addressed developmental differences among children and adolescents and their influence on the participatory approaches taken. Six stages in the development of a resource or intervention, where child and family co-researchers could participate, were identified and analysis of the included studies with reference to these stages revealed a need to involve co-researchers more in the later stages of resource and intervention development. This review acknowledges the difficulties that authors may have in adequately reporting participatory approaches within tight word limits imposed by academic journals. It concludes that, due to the complex nature of research involving participatory approaches, the development of dedicated reporting guidelines would provide greater direction to authors and encourage their claims to be grounded in research data.

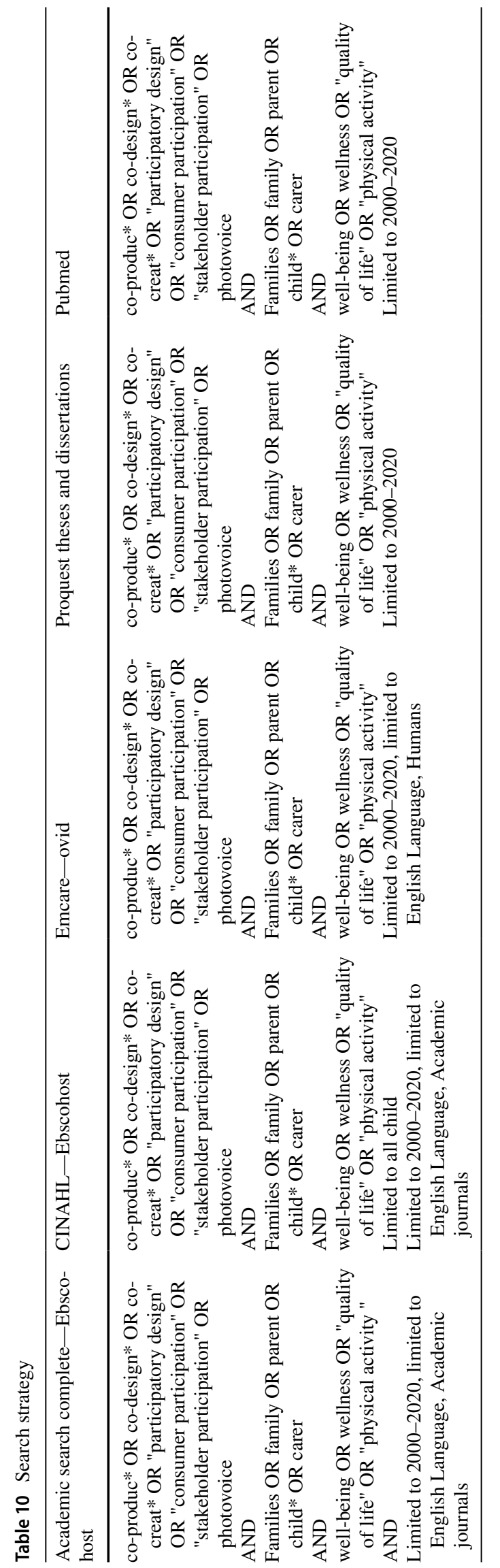




\section{Appendix 1}

See Appendix Table 10 . as you give appropriate credit to the original author(s) and the source, provide a link to the Creative Commons licence, and indicate if changes were made. The images or other third party material in this article are

Table 11 Proposed checklist for sufficiency of reporting of the participatory approach

\section{Checklist item}

1. Is the intention behind the participatory approach described? The authors should explain why a participatory approach was used

2. Is there a description of where the participatory approach took place? This should include characteristics of community or named geographical area and details on where the participatory approach took place (e.g. school, hospital)

3. Is there a description of who facilitated the participatory approach? Details of their profession (e.g. not just 'authors' or 'researchers') and their expertise in research/ participatory approaches should be provided

4. Is there a description of who was involved in the participatory approach? Details on the number of co-researchers, their characteristics (e.g. gender, age), recruitment, training (if required)

5. Is a description of the intervention or resource provided? Description of intervention or resource

6. Are descriptions of the phases and methods of participatory approach provided? Description of methods, phases (if relevant) and activities

7. Are descriptions of the intensity and schedule provided? Relevant detail for study should be provided

8. Is the intention of participatory approach evaluated? Description of evaluation and outcome should be provided

9. Is there a description of how shared decision making was facilitated? Could involve any of the following: description of if or when shared decision making took place, type of shared decision making, how they involved the co-researchers in shared decision making, facilitators and barriers to shared decision making

10. Do the authors report on end user input into the final resource or intervention? Description of how co-researchers gave their input, gave specific examples of end user ideas that were used in the intervention in the results section of their paper, counted the number of ideas that coresearchers contributed during the $P A$

\section{Appendix 2}

\section{See Appendix Table 11.}

Acknowledgements This work was supported by Three Rivers Department of Rural Health, Charles Sturt University. Three Rivers is funded by the Australian Government under the Rural Health Multidisciplinary Training Program. Ms. Georgia Gray and Prof. Deb Warr who contributed to early stages of planning and conduct of the review.

Authors' Contributions KF conceived of the study, participated in its design and coordination, interpretation of the data and drafted the manuscript; RP conceived of the study, participated in its design, interpretation of the data, review and editing of the manuscript; KJ participated in its design, interpretation of the data, review and editing of the manuscript; KA participated in interpretation of the data, review and editing of the manuscript; $\mathrm{MN}$ participated in interpretation of the data, review and editing of the manuscript; TB participated in the study design and investigation. All authors read and approved the final manuscript.

Funding Open Access funding enabled and organized by CAUL and its Member Institutions.

\section{Declarations}

Conflict of interest The authors declared that they have no conflict of interest.

Open Access This article is licensed under a Creative Commons Attribution 4.0 International License, which permits use, sharing, adaptation, distribution and reproduction in any medium or format, as long included in the article's Creative Commons licence, unless indicated otherwise in a credit line to the material. If material is not included in the article's Creative Commons licence and your intended use is not permitted by statutory regulation or exceeds the permitted use, you will need to obtain permission directly from the copyright holder. To view a copy of this licence, visit http://creativecommons.org/licenses/by/4.0/.

\section{References}

Abrines, J. N., Abbiss, M., Wray, J., Ashworth, J., Brown, K. L., \& Cairns, J. (2015). CHILDSPLA: a collaboration between children and researchers to design and animate health states. Child: Care, Health and Development, 41(6), 1140-1151.

Aceves-Martins, M., Llauradó, E., Tarro, L., Moriña, D., Papell-Garcia, I., Prades-Tena, J., et al. (2017). A school-based, peer-led, social marketing intervention to engage Spanish adolescents in a healthy lifestyle ("We are cool"-Som la pera study): A parallel-cluster randomized controlled study. Childhood Obesity, 13(4), 300-313.

Anselma, M., Altenburg, T. M., Emke, H., van Nassau, F., Jurg, M., Ruiter, R. A. C., et al. (2019). Co-designing obesity prevention interventions together with children: Intervention mapping meets youth-led participatory action research. International Journal of Nutrition and Physical Activity, 16, 130.

Baum, F., MacDougall, C., \& Smith, D. (2006). Participatory action research. Journal of Epidemiology and Community Health, 60, 854-857.

Bartholomew, L. K., Parcel, G. S., \& Kok, G. (1998). Intervention mapping: A process for developing theory- and evidence-based health education programs. Health Education \& Behavior, 25(5), 545-563.

Biediger-Friedman, L., Crixell, S. H., Silva, M., Markides, B. R., \& Smith, K. S. (2016). User-centered design of a Texas WIC app: A 
focus group investigation. American Journal of Health Behavior, 40(4), 461-471.

Boutron, I., Moher, D., Altman, D. G., Schulz, K. F., \& Ravaud, P. (2008). Extending the CONSORT statement to randomised trials of nonpharmacologic treatment: Explanation and elaboration. Annals of Internal Medicine, 148, 295-310.

Boutron, I., Altman, D. G., Moher, D., Schulz, K. F., \& Ravaud, P. (2017). CONSORT statement for randomized trials of nonpharmacologic treatments: A 2017 update and a CONSORT extension for nonpharmacologic trial abstracts. Annals of Internal Medicine, 167(1), 40-47.

Boyce, T., \& Brown, C. (2017). Engagement and Participation for Health Equity. World Health Organization. https://www.euro. who.int/_data/assets/pdf_file/0005/353066/Engagement-andParticipation-HealthEquity.pdf

Bradbury-Jones, C., Isham, L., \& Taylor, J. (2018). The complexities and contradictions in participatory research with vulnerable children and young people: A qualitative systematic review. Social Science and Medicine, 215, 80-91.

Cafazzo, J. A., Casselman, M., Hamming, N., Katzman, D. K., \& Palmert, M. R. (2012). Design of an mHealth app for the selfmanagement of adolescent type 1 diabetes: A pilot study. Journal of Medical Internet Research, 14(3), e70.

Carlton, J. (2013). Developing the draft descriptive system for the child amblyopia treatment questionnaire (CAT-Qol): A mixed methods study. Health Quality of Life Outcomes, 11, 174.

Clarivate Analytics. (2013). EndNote X9. Philadelphia, PA.

Convention on the rights of the child. (1989). Treaty no. 27531.United Nations Treaty Series, 1577, pp. 3-178. https:// treaties.un.org/doc/Treaties/1990/09/19900902\%2003-14\% 20AM/Ch_IV_11p.pdf

Den Heijer, A. E., Groen, Y., Tucha, L., Fuermaier, A. B. M., Koerts, J., Lange, K. W., et al. (2016). Sweat it out? The effects of physical exercise on cognition and behaviour in children and adults with ADHD: A systematic literature review. Journal of Neural Transmission, 124(Suppl. 1), S3-S26.

Druin, A. (2002). The role of children in the design of new technology. Behaviour \& Information Technology, 21(1), 1-25.

Durose, C., Needham, C., Mangan, C., \& Rees, J. (2017). Generating 'good enough' evidence for co-production. Evidence \& Policy, 13(1), 135-151.

Eyles, H., Jull, A., Dobson, R., Firestone, R., Whittaker, R., Te Morenga, L., et al. (2016). Co-design of mHealth delivered interventions: A systematic review to assess key methods and process. Current Nutrition Reports, 5, 160-167.

Freire, P. (1972). Pedagogy of the Oppressed. Herder and Herder.

Gobat, N., Littlecott, H., Williams, A., McEwan, K., Stanton, H., Robling, M., et al. (2021). Developing a whole-school mental health and wellbeing intervention through pragmatic formative process evaluation: A case-study of innovative local practice within The School Health Research network. BMC Public Health, 21,154 .

Gillespie, J., Magee, E., White, A., \& Stewart, L. (2019). Eat, play, learn well-a novel approach to co-production and analysis grid for environments linked to obesity to engage local communities in a child healthy weight action plan. Public Health, 166(1), 99-107.

Hamilton, K., Richardson, M., Owens, T., Yerby, L. G., Lucky, F. L., \& Higginbotham, J. C. (2017). Using photovoice to identify the physical activity practices of children residing in Alabama's black belt region. Journal of Community Practice, 25(3/4), 488-503.

Hannay, J., Dudley, R., Milan, S., \& Leibovitz, P. K. (2013). Combining photovoice and focus groups: Engaging Latina teens in community assessment. American Journal of Preventive Medicine, 44(3), S215-S224.

Hardt, J., Canfell, O. J., Walker, J. L., Webb, K.-L., Brignano, S., Peu, T., et al. (2020). Healthier together: Co-design of a culturally tailored childhood obesity community prevention program for Māori \& pacific islander children and families. Health Promotion Australia, 32(Suppl. 1), 143-154.

Hart, R. (1997). Children's Participation: The Theory and Practice of Involving Young Citizens in Community Development and Environmental Care. Routledge.

Hidding, L. M., Chinapaw, M. J. M., Belmon, L. S., \& Altenburg, T. M. (2020). Co-creating a 24-hour movement behavior tool together with 9-12-year-old children using mixed-methods: MyDailyMoves. International Journal of Behavioral Nutrition and Physical Activity, 17, 63.

Hill, M. (2006). Children's voices on ways of having a voice: Children's and young people's perspectives on methods used in research and consultation. Childhood, 3(1), 69-89.

Hoffman, T. C., Erueti, C., \& Glasziou, P. P. (2014). Better reporting of interventions: template for intervention description and replication (TIDieR) checklist and guide. BMJ, 348, g1687.

Hommel, K. A., Carmody, C., Hershey, A. D., Holbein, C., KabboucheSamaha, M., Peugh, J., \& Powers, S. (2020). Digital therapeutic self-management intervention in adolescents with migraine: Feasibility and preliminary efficacy of "migraine manager." Headache, 60, 1103-1110.

Hong, Q. N., Pluye, P., Fàbreques, S., Bartlett, G., Boardman, F., Cargo, M., et al. (2018). Mixed methods appraisal tool (MMAT), version 2018. Registration of Copyright (\#1148552), Canadian Intellectual Property Office, Industry Canada.

Hsich, H.-F., \& Shannon, S. E. (2005). Three approaches to qualitative content analysis. Qualitative Health Research, 15(9), 1277-1288.

Hudson, M., Milne, M., Reynolds, P., Russell, K., \& Smith, B. (2010). Te Ara Tika Guidelines for Māori Research Ethics: A Framework for Researchers and Ethics Committee Members. Health Research Council.

Hussain, S. (2010). Empowering marginalised children in developing countries through participatory design processes. Co-Design, 6(2), 99-117.

Lindqvist, A. K., Löf, M., Ek, A., \& Rutberg, S. (2019). Active school transportation in winter conditions: Biking together is warmer. International Journal of Environmental Research and Public Health, 17(5), 1524.

Mammen, S., Sano, Y., Braun, B., \& Fost Maring, C. (2019). Shaping core health messages: Rural, low-income mothers speak through participatory action. Journal Health Communication, $34(10), 1141-1149$.

McLaughlin, H. (2006). Involving young service users as coresearchers: Possibilities, benefits and costs. British Journal of Social Work, 36, 1395-1410.

Milnes, L. J., McGowan, L., Campbell, M., \& Callery, P. (2013). Developing an intervention to promote young people's participation in asthma review consultations with practice nurses. Journal of Advanced Nursing, 69(1), 91-101.

Montreuil, M., Bogossian, A., Laberge-Perrault, E., \& Racine, E. (2021). A review of approaches, strategies and ethical considerations in participatory research with children. International Journal of Qualitative Methods, 20, 1-15.

Morales-Campos, D. Y., Parra-Medina, D., \& Esparza, L. A. (2015). Picture this! Using participatory photo mapping with Hispanic girls. Family \& Community Health, 38(1), 44-54.

Morgan, K., Van Godwin, J., Darwent, K., \& Fildes, A. (2019). Formative research to develop a school-based, communitylinked physical activity role model programme for girls: CHoosing active role models to inspire girls (CHARMING). BMC Public Health, 19, 437.

Mulvale, A., Miatello, A., Hackett, C., \& Mulvale, G. (2016). Applying experience-based co-design with vulnerable populations: Lessons from a systematic review of methods to involve patients, families and service providers in child and youth 
mental health service improvement. Patient Experience Journal, 3(1), 15.

Page, M. J., McKenzie, J. E., Bossuyf, P. M., Boutron, I., Hoffman, T. C., Mulrow, C. D., et al. (2021). The PRISMA 2020 statement: an updated guideline for reporting systematic reviews. British Medical Journal, 372, 71.

Preston, N., Magallón, S., Hill, L. J. B., Andrews, E., Ahern, S. M., \& Mon-Williams, M. (2017). A systematic review of high quality randomized controlled trials investigating motor skill programmes for children with developmental coordination disorder. Clinical Rehabilitation, 31(7), 857-870.

Richardson, L. (2014). Engaging the public in policy research: Are community researchers the answer? Politics and Governance, 2(1), 32-44.

Ruland, C. M., Starren, J., \& Vatne, T. M. (2008). Participatory design with children in the development of a support system for patient centred care in pediatric oncology. Journal of Biomedical Informatics, 41(4), 624-635.

Schwarzer, R., Lippke, S., \& Ziegelmann, J. P. (2008). Health action process approach: A research agenda at the Freie Universität Berlin to examine and promote health behavior change. European Journal of Health Psychology, 16(3), 157-160.

Shier, H. (2001). Pathways to participation: Openings, opportunities, and obligations. Children \& Society, 15(2), 107-117.

Sockolow, P., Schug, S., Zhu, J., Smith, T. J., Senathirajah, Y., \& Bloom, S. (2017). At risk adolescents as experts in a new requirements elicitation procedure for the development of a smart phone psychoeducational trauma informed care application. Journal of Informatics for Health and Social Care, 42(1), 77-96.

Stalberg, A., Sandberg, A., Soderback, M., \& Larsson, T. (2016). The child's perspective as a guiding principle: Young children as co-designers in the design of an interactive application meant to facilitate participation in healthcare situations. Journal of Biomedical Informatics, 61, 149-158.

Swinburn, B., Egger, G., \& Raza, F. (1999). Dissecting obesogenic environments: The development and application of a framework for identifying and prioritizing environmental interventions for obesity. Preventive Medicine, 29(6), 563-570.

Thomas, N., \& O'Kane, C. (1998). The ethics of participatory research with children. Children \& Society, 12, 336-348.

Warnestal, P., Svedberg, P., Lindberg, S., \& Nygren, J. M. (2017). Effects of using child personas in the development of a digital peer support service for childhood cancer survivors. Journal of Medical Internet Research, 19(5), e161.

Warren, C. M., Dyer, A., Blumenstock, J., \& Gupta, R. S. (2016). Leveraging mobile technology in a school-based participatory asthma intervention: Findings from the student media-based asthma research team (SMART) study. American Journal of Health Education, 47(2), 59-70.

Yarosh, S., \& Schueller, S. M. (2017). Happiness inventors: Informing positive computing technologies through participatory design with children. Journal of Medical Internet Research, 19(1), e14.

Young, N. L., Wabano, M. J., Burke, T. A., Ritchie, S. D., Mishibinijima, D., \& Corbiere, R. G. (2013). A process for creating the Aboriginal children's health and well-being measure (ACHWM). Revue Canadienne De Sante Publique, 104(2), e136-e141.

Publisher's Note Springer Nature remains neutral with regard to jurisdictional claims in published maps and institutional affiliations. 